NASA TECHNICAL NOTE

N
0
0
0
$z$
$z$
$z$

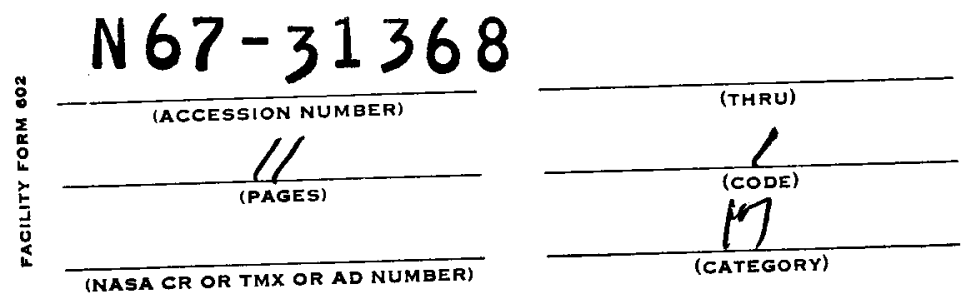

KINETICS OF THE

FLUORINATION OF BERYLLIUM

by Patricia M. O'Donnell

Lewis Research Center

Cleveland, Obio

National aERONAUtics AND SPACE ADMINISTRATION • WASHINGTON, D. C. • JULY 1967 


\section{KINETICS OF THE FLUORINATION OF BERYLLIUM}

By Patricia M. O'Donnell

\section{Lewis Research Center}

Cleveland, Ohio

\section{NATIONAL AERONAUTICS AND SPACE ADMINISTRATION}




\section{KINETICS OF THE FLUORINATION OF BERYLLIUM \\ by Patricia M. O'Donnell \\ Lewis Research Center}

\section{SUMMARY}

The kinetics of the reaction of sheet beryllium and gaseous fluorine to form beryllium fluoride were studied by means of the pressure drop method over the temperature range of $125^{\circ}$ to $775^{\circ} \mathrm{C}$ and at pressures from 20 to 700 torr. The reaction followed the

parabolic rate law $y^{2}=k t$, where $y$ is the amount of fluorine consumed per unit area of beryllium surface $(\mathrm{ml} / \mathrm{sq} \mathrm{cm}), \mathbf{k}$ is the parabolic rate constant, and $t$ is the time $(\mathrm{min})$. Parabolic rate constants were calculated, and activation energies are given. A change of slope in the plot of the rate constant against reciprocal temperature suggests a change in the nature of the reaction near $525^{\circ} \mathrm{C}$. Above $525^{\circ} \mathrm{C}$ the crystal structure of the film changes from $\alpha$-quartz hexagonal to rhombic tridymite. Beryllium is identified as the diffusing species.

\section{INTRODUCTION}

Beryllium, because of its light weight, high-temperature strength, thermal conductivity, and neutron-moderating characteristics, is of interest for application in reactors, satellites, and future supersonic aircraft. The beryllium-oxygen reaction has been extensively studied, and it involves the outward diffusion of beryllium ions (ref. 1). At high temperatures the initially protective oxide film is no longer protective (ref. 2) because of the onset of breakaway oxidation. Several other beryllium-gas reactions have been investigated (ref. 3) including the reactions of beryllium with carbon monoxide and with carbon dioxide (ref. 4). Although data appear in the literature (refs. 5 and 6) concerning the thermodynamic properties of beryllium fluoride $\left(\mathrm{BeF}_{2}\right)$, little is reported on the kinetics of the beryllium-fluorine reaction. This report presents the kinetics of the reaction of fluorine with beryllium and the effects of temperature and pressure on the reaction rate.

\section{APPARATUS AND PROCEDURE}

The experimental apparatus and the procedure used to measure the rate of fluorina- 
tion are described in reference 7 . The high-purity-beryllium test pieces were strips measuring 1.27 by 15.24 by 0.012 centimeter with a 0.5 -centimeter-diameter hole drilled in one end for handling. The strips were cleaned with a solution of nitric and hydrofluoric acids $\left(\mathrm{HNO}_{3}-\mathrm{HF}\right)$, with a detergent, with water, and finally with an acetone rinse (ref. 8). The strips were preheated for 0.5 hour at $525^{\circ} \mathrm{C}$. After reaction the products were characterized by $\mathrm{X}$-ray diffraction and cross-section metallography.

\section{RESULTS AND DISCUSSION}

In figures 1 and 2 the reaction is shown to follow the parabolic rate law $\mathrm{y}^{2}=\mathrm{kt}$, where $y$ is the amount of fluorine consumed (at STP) per unit area of beryllium surface $(\mathrm{ml} / \mathrm{sq} \mathrm{cm}), \mathrm{k}$ is the parabolic rate constant, and $\mathrm{t}$ is the time ( $\mathrm{min})$. All the data over the temperature and pressure ranges studied can be described by this parabolic rate law. A reaction similar to breakaway oxidation was not found with fluorine; the film continued to be protective.

The values of the parabolic rate constants are listed in table I. The parabolic rate constant is plotted as a function of temperature at a pressure of 200 torr in figure 3 . In this figure the rate of reaction shows a negative temperature dependence in the low temperature range. This behavior is not unique because in heterogeneous systems where the rate of reaction is determined by diffusion in a solid layer a simple temperature dependence of the net process is not always found. Reactions of this type are complex processes involving the diffusion of at least one ion and electrons across the film through accessible diffusion sites. The number and accessibility of these sites can change at different temperatures; thus, the rate of reaction can decline with rising temperature. A break in the curve appears at $525^{\circ} \mathrm{C}$. At this point the activation energy $\left(\Delta \mathrm{H}_{\mathrm{A}}\right)$ changes from -0.8 kilocalorie per mole at the low temperatures to 8 kilocalories per mole at the high temperatures. The following equations define the variation of the rate constant in the two temperature ranges:

$$
\begin{aligned}
& \mathrm{k}=0.4 \times 10^{-5} \mathrm{e}^{800 / \mathrm{RT}}(\mathrm{ml} / \mathrm{sq} \mathrm{cm})^{2} / \mathrm{min} \text { for } 125^{\circ} \text { to } 525^{\circ} \mathrm{C} \\
& \mathrm{k}=1.5 \times 10^{-2} \mathrm{e}^{-8000 / \mathrm{RT}}(\mathrm{ml} / \mathrm{sq} \mathrm{cm})^{2} / \mathrm{min} \text { for } 525^{\circ} \text { to } 775^{\circ} \mathrm{C}
\end{aligned}
$$

where $k$ is the rate constant, $R$ is the gas constant, and $T$ is the absolute temperature.

A $\log -\log$ plot of the rate constant as a function of the fluorine pressure is shown in figure 4. The reaction is approximately first order with respect to fluorine pressure.

The low-temperature film is identified as $\alpha$-quartz hexagonal $\mathrm{BeF}_{2}$, and the hightemperature film is identified as rhombic tridymite $\mathrm{BeF}_{2}$ (ref. 9). A study was made 
of the reaction of $\alpha$-quartz $\mathrm{BeF}_{2}$ with fluorine gas at a temperature of $675^{\circ} \mathrm{C}$ and a - fluorine pressure of 200 torr. No apparent change was observed in that no rhombic tridymite form was found. This observation would lead to the assumption that for the hightemperature reactions the $\alpha$-quartz hexagonal $\mathrm{BeF}_{2}$ is not formed first and then converted to the tridymite form but that the tridymite $\mathrm{BeF}_{2}$ is formed directly. Films formed at low temperatures were dull, nonreflecting surfaces, while those produced at high temperatures resembled shiny mirrors.

When fluorine is first introduced into the system, it contacts bare beryllium metal and reacts with it to form $\mathrm{BeF}_{2}$. As the time of contact increases, a layer of $\mathrm{BeF}_{2}$ is built up. For continuation of the reaction either fluorine or beryllium must move across the film barrier. The reacted metal strips are shown in figures 5 and 6 . Figure 5 shows a reacted metal strip after fluorine exposure at a temperature of $625^{\circ} \mathrm{C}$ and a pressure of 630 torr. The mirrorlike characteristics of the surface are evident. Etched cross sections of the strip show that the reaction is not a grain boundary attack but is a transgranular attack. The photomicrograph in figure 6 is a cross section showing the $\mathrm{BeF}_{2}$ coating. The boundary between the beryllium and the $\mathrm{BeF}_{2}$ is not well defined but beryllium is seen as light areas extending into the film. This appearance would indicate that outward diffusion of beryllium is taking place. Identification of the diffusing species was determined by the pattern of two $\mathrm{BeF}_{2}$ surfaces growing towards one another. Fusion of the impinging fluoride layers would indicate beryllium diffusion (ref. 10). Two of the beryllium strips were clamped together along the 1.27 -centimeter side with a 0.012 centimeter-thick Monel ribbon inserted between the plates to form a small wedge angle. The sample was then inserted into the apparatus and run at a temperature of $675^{\circ} \mathrm{C}$ and a fluorine pressure of 400 torr according to standard procedures. After it was removed from the furnace, the sample was set in plastic and dry polished. Figure 7 is a cross section showing that the surfaces have fused together; this figure demonstrates that beryllium is diffusing during fluorination at high temperature.

\section{CONCLUDING REMARKS}

The fluorination of beryllium is both temperature and pressure dependent. The pressure dependency is approximately first order with respect to fluorine pressure. The reaction is diffusion controlled and follows a parabolic rate law. The beryllium fluoride layer that is formed on the beryllium substrate is continually protective, and no break- 
away oxidation is observed. Cross-section metallography has shown that beryllium is the diffusing species.

Lewis Research Center,

National Aeronautics and Space Administration,

Cleveland, Ohio, February 14, 1967,

128-31-04-01-22.

\section{REFERENCES}

1. Jepson, W. B.: The Oxidation of Beryllium. Research (London), vol. 15, 1962, pp. 288-294.

2. Aylmore, D. W.; Gregg, S. J.; and Jepson, W. B.: The High Temperature Oxidation of Beryllium. Part I. In Dry Oxygen. J. Nucl. Materials, vol. 2, no. 2, June 1960, pp. 169-175.

3. Pemsler, J. P. ; and Anderson, R. W.: Literature Survey of Gases in Beryllium. Rep. No. NMI-9805, Nuclear Metals, Inc., Jan. 17, 1961.

4. Gregg, S. J.; Hussey, R. J.; and Jepson, W. B.: Oxidation of Beryllium in Carbon Dioxide and Carbon Monoxide. Nature, vol. 186, 1960, pp. 468-469.

5. Taylor, A. R., Jr.: Recent Calorimetric Studies of Beryllium Fluoride. Proceedings of the Second Meeting of the Applied Physics Lab. Working Group on Thermochemistry, Alexandria, Va., June 3-4, 1964. Vol. I. CPIA Publ. 54, Johns Hopkins University, Aug. 1964, pp. 85-86. (Available from DDC as AD-451711.)

6. Greenbaum, Michael A. ; Foster, James N.; Arin, M. Louis; and Farber, Milton: The Thermodynamic and Physical Properties of Beryllium Compounds. I. Enthalpy and Entropy of Vaporization of Beryllium Fluorides. J. Phys. Chem., vol. 67 , no. 1 , Jan. 1963 , pp. 36-40.

7. O'Donnell, Patricia M.; and Spakowski, A. E.: The Fluorination of Copper. Electrochem. Soc. J., vol. 111, no. 6, June 1964, pp. 633-636.

8. Beaver, W. W.; and Stonehouse, A. J.: Beryllium - Surface Treatment and Coatings. Rep. No. BBC-TR-329, Brush Beryllium Co., Aug. 1963.

Q. Korcnev, Ya. M.: Rhombic Modification of Berylliüm Fluoride. Akad. Nauk Doklady, SSSR, vol. 147, 1962, pp. 846-848.

10. Schnizlein, J. G.; Woods, J. D.; Bingle, J. D.; and Vogel, R. C.: Identification of the Diffusing Species in Uranium Oxidation. Electrochem. Soc. J., vol. 107, no. 9, Sept. 1960, pp. 783-785. 
TABLE I. - SUMMARY OF TEMPERATURE AND

PRESSURE CONDITIONS AND CALCULATED

PARABOLIC RATE CONSTANTS

\begin{tabular}{|c|c|c|}
\hline $\begin{array}{c}\text { Temperatire, } \\
{ }^{\circ} \mathrm{C}\end{array}$ & $\begin{array}{c}\text { Pressure, } \\
\text { torr }\end{array}$ & $\begin{array}{c}\text { Parabollc rate constant, } \\
\mathbf{k}, \\
(\mathrm{ml} / \mathrm{sq} \mathrm{cm})^{2} / \mathrm{min}\end{array}$ \\
\hline 125 & 200 & $1.05 \times 10^{-5}$ \\
\hline 225 & 200 & $0.94 \times 10^{-5}$ \\
\hline 525 & 60 & $0.20 \times 10^{-5}$ \\
& 200 & .69 \\
& 630 & 3.77 \\
& 700 & 5.70 \\
\hline 575 & 200 & $3.30 \times 10^{-5}$ \\
\hline 625 & 200 & $17.0 \times 10^{-5}$ \\
& 630 & 41.0 \\
\hline 675 & 20 & $4.03 \times 10^{-5}$ \\
& 40 & 9.70 \\
& 60 & 16.30 \\
& 200 & 69.20 \\
\hline 775 & 60 & $130 \times 10^{-5}$ \\
& 200 & 280 \\
\hline
\end{tabular}

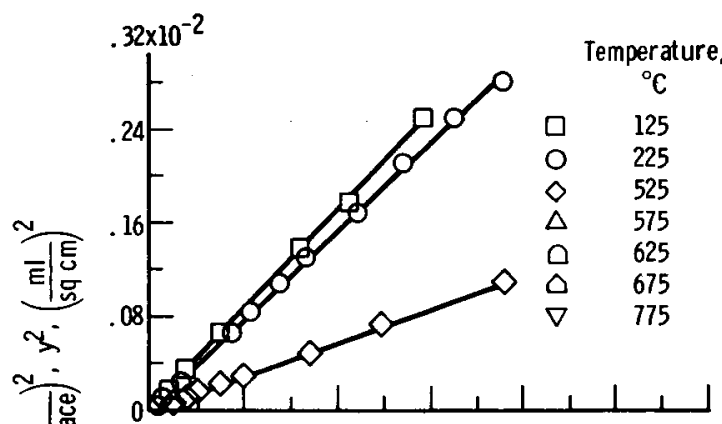

(a) Low-temperature range $\left(125^{\circ}\right.$ to $\left.525^{\circ} \mathrm{C}\right)$.

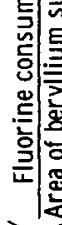

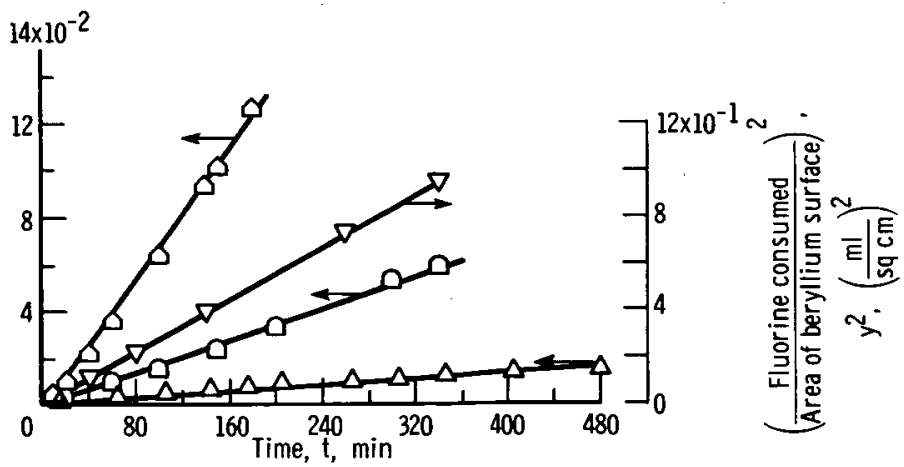

(b) High-temperature range $\left(575^{\circ}\right.$ to $\left.775^{\circ} \mathrm{C}\right)$.

Figure 1. - Effect of temperature on fluorination of beryllium. Pressure, 200 torr. 

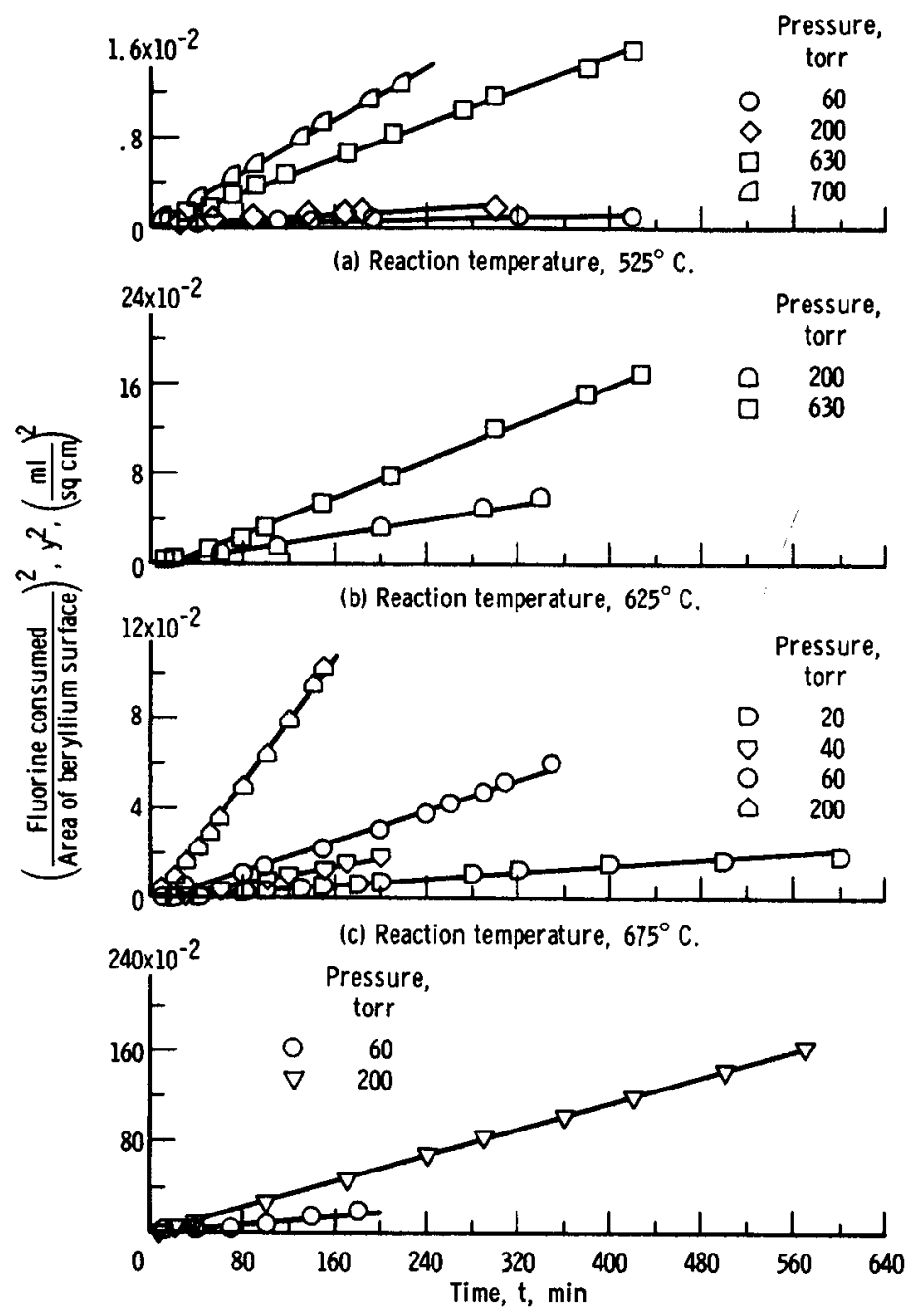

(d) Reaction temperature, $775^{\circ} \mathrm{C}$.

Figure 2. - Effect of pressure on fluorination of beryllium. 


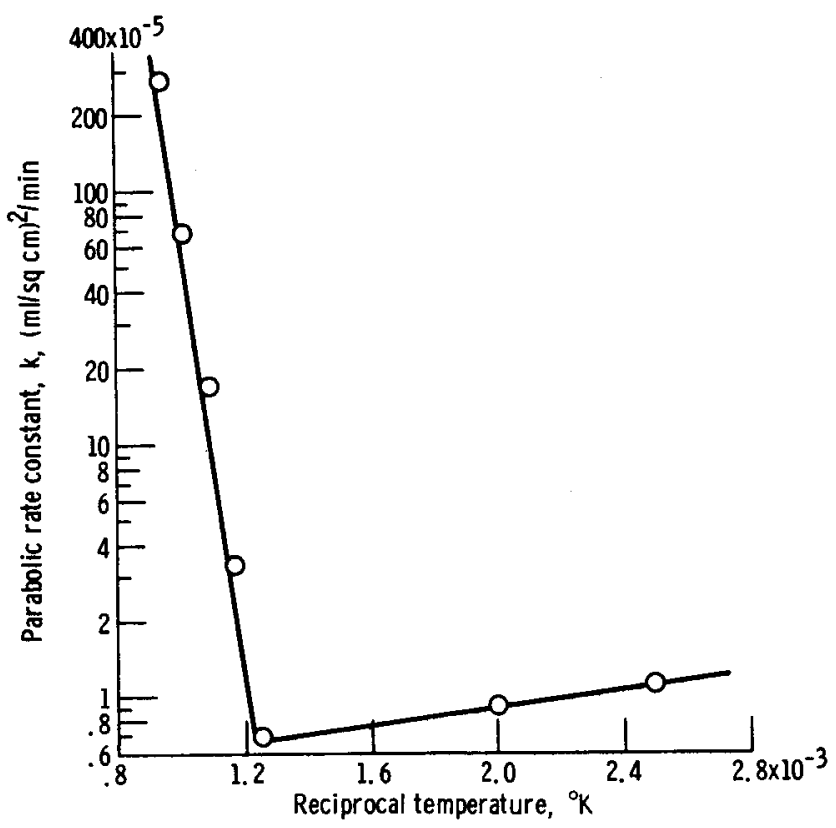

Figure 3. - Effect of temperature on parabolic rate constant. Pressure, 200 torr.

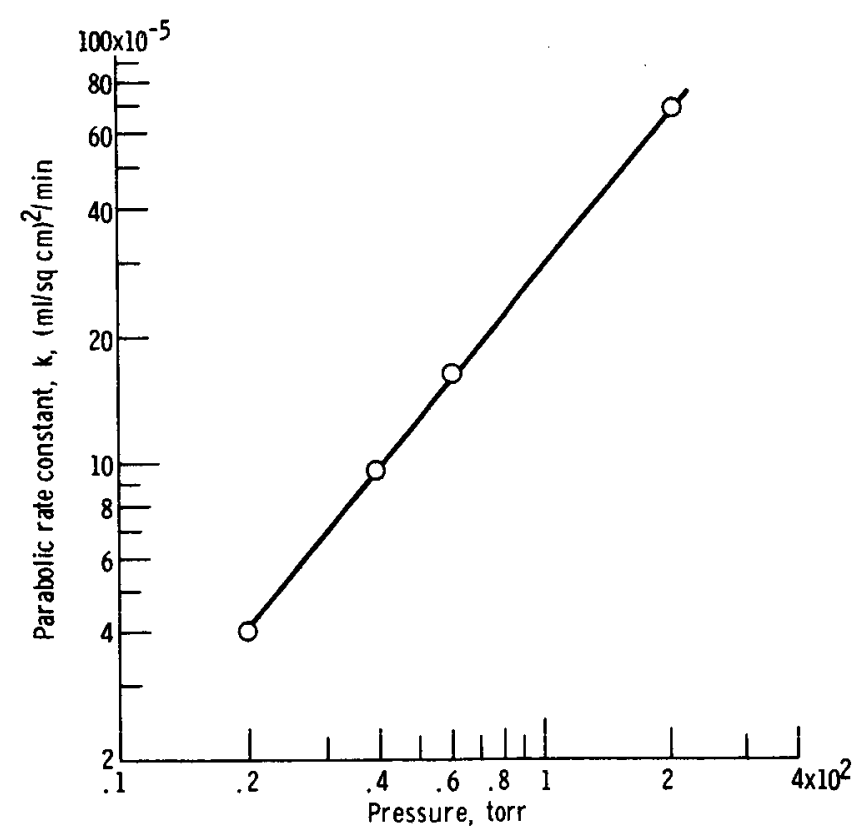

Figure 4. - Effect of pressure on parabolic rate constant.

Temperature, $675^{\circ} \mathrm{C}$. 


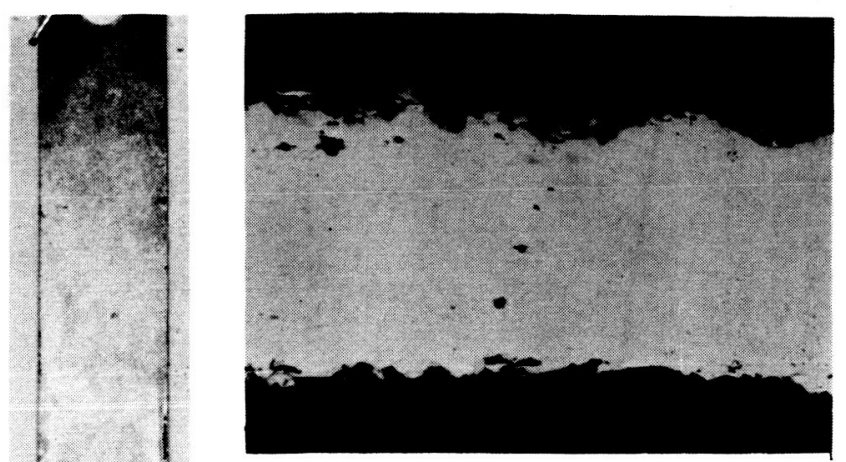

(b) Cross section unetched. $\times 250$.

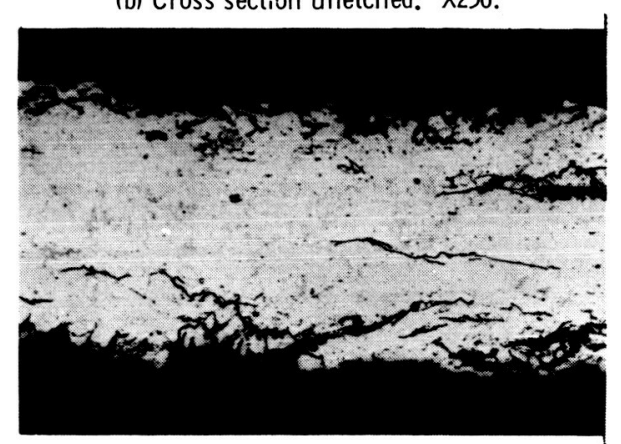

(c) Cross section etched in hydrogen fluoride for 10 seconds. X250.

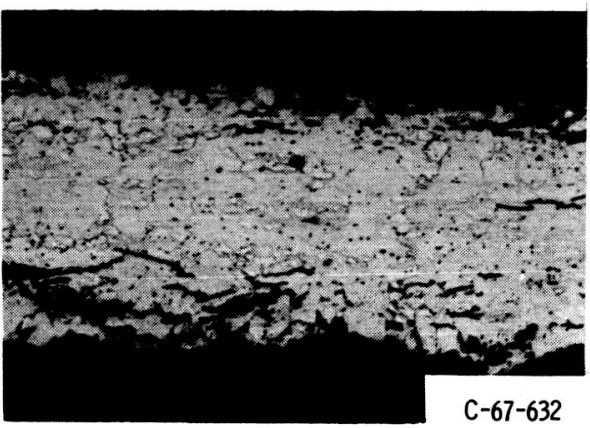

(a) Corrosion strip. (d) Cross section etched in hydrogen fluoride for 20 X1.5. seconds. X250.

Figure 5. - Reacted metal strip after fluorine exposure. Temperature, $625^{\circ} \mathrm{C}$; pressure, 630 torr. (Reúuced 40 percent in printing.) 


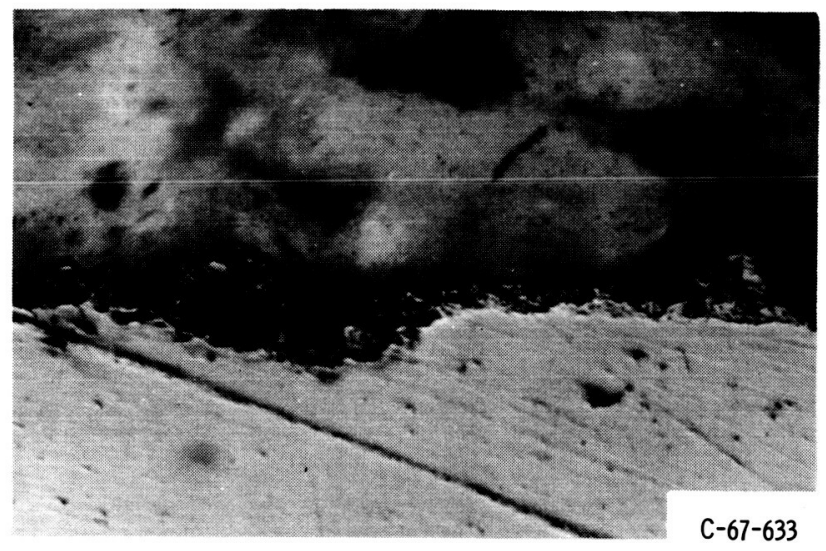

Figure 6. - Cross section showing beryllium fluoride coating. X500. (Reduced 25 percent in printing.)

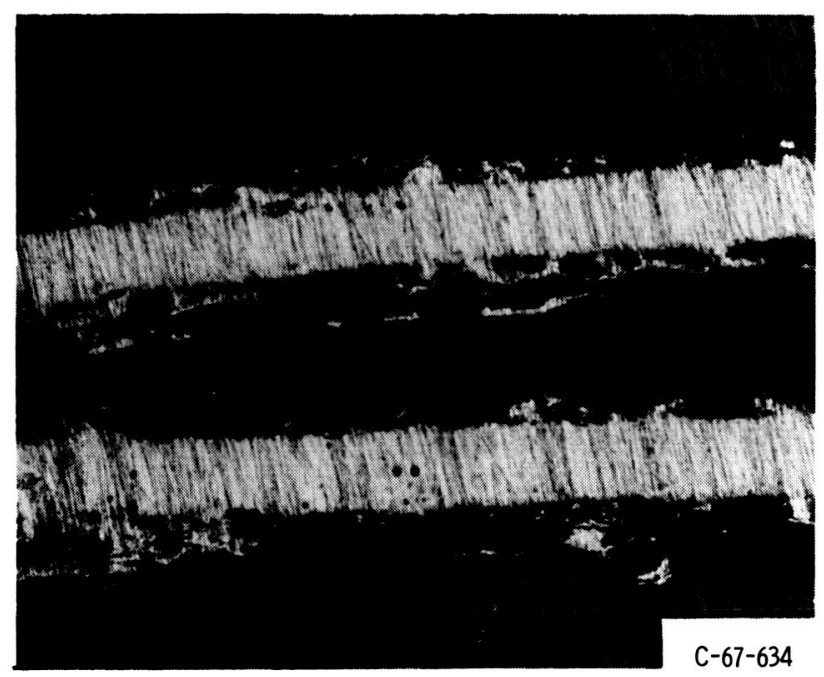

Figure 7. - Cross section showing that surfaces have fused together. X75. (Reduced 25 percent in printing.) 